\title{
Resposta à pergunta: o que é enegrecimento?*
}

\section{André Luis de Oliveira Mendonça}

Instituto de Medicina Social - Universidade do Estado do Rio de Janeiro

alomendonca@gmail.com

Recebido em 11/09/2017

Aceito em 01/10/2017
Dedicado às minhas tias Lourdes e Ditinha, à minha tia de consideração Almerinda (in memoriam), às minhas tias Carminha, Judith e Helena (in memoriam) e à minha mãe, “Tia Mãezinha” (in memoriam) sete mulheres que foram minhas grandes formadoras na arte do 'enegrecimento'.
Foi quando ela [a personagem Maria Cristina] me perguntou se tinha um amigo meu [a personagem Augusto] que tinha se demitido por achar o trabalho na universidade reacionário, ao que respondi explicando que os termos dele não eram tão radicais assim, mas que ele criticava, sim, que considerássemos textos de filósofos europeus e de seus principais intérpretes no nosso caso, em especial os intérpretes americanos de Kant - como uma dádiva a qual possamos, ou devamos, acolher com júbilo e gratidão, pois - segundo ele, o que, aliás, não é dizer nada de novo - tudo tem um preço: que preço pagamos por nos regozijarmos e orgulharmo-nos - lendo Kant?

Kant em coma, André Rios

* Este ensaio é uma versão modificada de texto lido na roda de conversa "Quem Estamos Formando? Para Que e Como Realizamos essa 'Missão'?", concebida e realizada como encerramento da disciplina "Crise e Saúde”, ministrada pelos professores Ruben Mattos, Paulo Henrique Rodrigues, Ronaldo Teodoro e por mim, na pós-graduação em saúde coletiva do IMS-UERJ, no primeiro semestre de 2017. Redigi meu texto original como uma resposta à pergunta colocada por Roberta Dorneles (participante da disciplina e minha orientanda de doutorado): "O que é formação, afinal?". Aqui, inspirado e, ao mesmo tempo contraposto a Kant, eu tento responder o que vem a ser aquilo que estou chamando de 'enegrecimento' sem que ninguém, entrementes, até onde sei, tenha posto a indagação abertamente. Aproveito o ensejo para agradecer aos professores e participantes da disciplina pela oportunidade prestimosa que nós tivemos de compartilhar ideias, experiências e, de modo especial, valores e afetos, o que propiciou inclusive a constituição de uma espécie de coletivo saúde sem crises, uma reação "espontânea" à trágica conjuntura sob a égide de um presidente golpista e de um governador inominável, para não aduzir outras figuras dantescas dos níveis executivo, legistativo e judiciário da nossa atual "democracia" nada montesquiana. 
Ao final do século XVIII, intelectuais europeus responderam à inquirição do pastor berlinense Johann Friedrich Zöllner, que, de modo provocativo, interrogara se algum "esclarecido" saberia lhe dizer o que significava, afinal, o esclarecimento sobre o qual tanto se falava. ${ }^{1}$ Sua motivação era hastear a bandeira em honra do matrimônio religioso contra o casamento civil (imaginem sua posição referente ao "casamento gay"...). Immanuel Kant forneceu a contribuição mais conhecida no texto Resposta à Pergunta: O que é Esclarecimento?,que, segundo Michael Foucault (2015), trata-se do texto em que, pela primeira vez na história da filosofia, um pensador se ocupou com uma questão crucial de seu tempo histórico como 'pura atualidade', tentando, com perdão da repetição, esclarecer como o "esclarecimento" viera a ser o que era, i.e, Kant teria inspirado, em certo sentido, a 'ontologia histórica' levada adiante sob novas bases pelo próprio Foucault.

Para Kant, o esclarecimento (iluminismo) enquanto traço essencial da modernidade seria, fundamentalmente, a saída da humanidade da "menoridade" da qual ela própria fora responsável ("culpada", é, na realidade, a palavra de conotação teológica que ele emprega); sendo, por conseguinte, "ousai saber" (sapere aude!), ou servir-se da própria razão sem tutela de outrem, o lema premente dos tempos modernos. Em suas palavras, continuamos agrilhoados à "menoridade" quando um livro faz as vezes do nosso próprio entendimento, quando um orientador espiritual faz as vezes da nossa própria consciência moral ou quando um médico faz as vezes da nossa própria dieta. Se admitirmos que nós ficamos a cada dia que passa mais dependentes dos experts para guiarmos nossas vidas em sociedade ou tomarmos decisões, podemos inferir que, paradoxalmente, o auge da "modernidade" coincide com o fato de termos nos tornado cada vez menos "maiores", no sentido kantiano do termo.

Para meu propósito central aqui, mais importante ainda é a constatação de que Kant foi um dos precursores do imaginário cultural pertencente à Bildung, cujo conteúdo basilar consiste em uma espécie de imperativo filosófico-pedagógico de formar, pela razão, as pessoas em sua integridade e integralidade, cultivando-as nas ciências, nas virtudes, nas artes etc. -, o que engendraria a possibilidade de o indivíduo formado no interior desse ideário fazer da sua própria vida uma espécie de obra de arte porque bela, boa, criativa e carregada de sentido. Pouco mais de um século depois, será Max Weber quem verá com grande pessimismo esse projeto de formação pretensamente total e plena, uma vez que a ciência não seria propícia a dar sentido último à vida das pessoas; ao contrário, seu êxito ou progresso, o da ciência, seria uma espécie de corolário do abandono das 'questões de sentido.'

Todavia, nesse pequeno ensaio, eu não pretendo adentrar os meandros da seara árida delineada acima, senão tão-somente apontar na direção de novas trilhas adstritas à questão da formação, tendo como objetivo 'suleador' a defesa esperançosa da ideia de 'Enegrecimento' como suprassunção possível do velho Esclarecimento Europeu, a partir de um relato de experiência formativa própria. Assim como o referido texto de Kant -publicado nos idos de 1784, na revista mensal Berlinische Monatsschrift de relativa circulação, e parodiado aqui por mim - é curto e fino em virtude de almejar atingir um público maior, eu gostaria que meu texto pudesse ser acessível ao maior número de pessoas possível, incluindo as minhas tias a quem ele é dedicado, caso todas estivessem vivas - exceto minha tia de consideração Almerinda, que jamais conseguiu se alfabetizar plenamente, embora nunca tenha desistido de tentar, até a morte e já idosa, ir além da capacidade de soletrar algumas palavras isoladas (jamais me redimirei da culpa de não ter tido competência para

1 De grande valor, sobretudo pela redescoberta de textos que haviam ficado no limbo da história, é a compilação de opúsculos sobre o esclarecimento intitulada justamente O que é Esclarecimento? (KANT, I.; et al, 2011), em grande parte respostas dirigidas diretamente à provocação do pastor Zöllner dadas "no calor da hora" por intelectuais da estirpe de Friedrich Schiller, Johann Herder, MosesMendelssohn, entre outros.

2 Se eu refiro Weber aqui é, talvez, em razão da minha participação no "I Colóquio Bildung: Ciência como Vocação", realizado em abril de 2017 no Vale Vêneto, especificamente na mesa-redonda em que tive o prazer e a honra de fazer parte juntamente com Juan Quejo, a quem aproveito para agradecer pelas excelentes trocas que mantivemos acerca da tarefa da universidade latino-americana no mundo de hoje. No colóquio, procurou-se repensar o clássico texto A ciência como vocação, tendo como horizonte histórico e conceitual a ideia de Bildung - amiúde traduzida por formação. Aproveito o ensejo também para agradecer pelo convite feito por André Cremonesi, Antonio Videira e Róbson dos Reis (organizadores do evento), bem como pela maravilhosa e aprazível oportunidade de ter "ensaiado", creio que pela primeira vez publicamente - embora ainda não tivesse me ocorrido o uso do termo naquela ocasião -, meus insigths acerca do 'enegrecimento' nas dependências de um ex-seminário Palotino. 
ajudá-la durante minha infância e adolescência, períodos em que convivi com ela. Infelizmente, ainda não havia para mim Paulo Freire...).

\section{Três pontos de vista sobre a formação}

Mesmo querendo fazer apenas um brevíssimo relato da minha experiência como docente, ainda curta porém intensa, permitir-me-ei (a mesóclise nem sempre é “temerária”...) dar uma rápida pincelada no quadro histórico e conceitual do problema da formação, tal como o meu olhar limitado, ou delimitado, apreende-o. Sem querer atentar, por ora, para a história da pedagogia ${ }^{3}$, pode-se dizer que há três grandes modalidades de concepção acerca da formação, ao longo da era moderna e contemporânea; não necessariamente sucessivas, posto que coexistentes e/ou conflituosas: vou aqui cunhá-las de formação iluminista ("esclarecida"), formação "pós-moderna" e formação democrática; cada uma delas, obviamente, contendo em si uma ampla variedade de vertentes. Vejamo-las de per si em piscadelas. ${ }^{4}$

A formação iluminista visa a tornar os "bárbaros" ou "primitivos" iguais aos "civilizados", conduzindo-os pelas mãos à "luz do conhecimento", ao "esclarecimento". Grosso modo, pode-se dizer que um dos principais vetores do conjunto de valores e princípios inerentes a esse tipo de formação é o 'formalismo'. Parte-se do pressuposto de que formar é repassar conhecimentos supostamente verdadeiros por meio de fórmulas, noções e conceitos, desconsiderando inteiramente, por um lado, o contexto em que tais saberes foram construídos e produzidos, por outro, o ambiente no qual os indivíduos "receptores" estão embebidos. Seja a criança de "tábula rasa" a aprender algo, supostamente pela primeira vez, seja o "primitivo" adulto a reaprender "corretamente", o que se pretende, em tese, é tirar as pessoas das "trevas da ignorância" e elevá-las à "sabedoria" através da transmissão abstrata de conteúdos legitimados por um determinado grupo (ideologia dominante?). Trata-se, portanto, de uma formação marcadamente padronizada e hierarquizada, além de amiúde desconectada da vida devido ao seu alto grau de "abstração".

A formação "pós-moderna" procura fazer de conta que os "civilizados" são iguais aos "bárbaros" ou "primitivos", descendo às "trevas" em que estes dois últimos se encontrariam. Embora ainda não tenha sido propriamente institucionalizada, essa concepção já impera há tempos em alguns campos do saber; costuma-se apontar a linguística como um caso emblemático de "pós-modernidade acadêmica" em função da separação (a rigor, superação da divisão) que os novos linguistas fazem entre língua e gramática normativa, valorizando os "erros" da primeira em detrimento da "correção" da última. ${ }^{5}$ Será justa a acusação?

Já a formação democrática representa uma ruptura com os pressupostos subjacentes às noções de civilização, barbárie, luz, trevas, entre outras, primando, desde o ponto de partida, pela igualdade das interações humanas e dos processos formativos: o outro não é alguém que preciso transformar em um "superior" igual a mim, tampouco eu devo me transmutar, artificialmente, em um "inferior" igual a ele ou ela; na realidade, nós sempre estamos, ou deveríamos estar, em uma relação de horizontalidade.

3 Franco Cambi (1999) traça um amplo quadro da história da pedagogia, indo da antiguidade à contemporaneidade. A rigor, ele mostra como se passou de uma história da pedagogia tradicional (dominada por concepções filosóficas idealizadas e normativas) para uma história da educação na qual as várias ciências da educação começaram a atentar para as práticas educativas concretas. Isso sem deixar de reconhecer que toda e qualquer teoria ou vertente pedagógica está sempre vinculada a correntes filosóficas específicas. A propósito dessa temática sobre a imbricação entre pensamento filosófico e educação (no caso, guiada pelo olhar das teorias sociais críticas), ver, por exemplo, Morrow\& Torres (1997).

4 O argumento desenvolvido nessa seção é inspirado livremente no livro O mestre ignorante, de Jacques Rancière, cujo conteúdo primordial foi belamente resumido na máxima extraída do ideário emancipatório e revolucionário atrelado a Joseph Jacotot: "Assim, o dever dos díscipulos de Jacques Jacotot é bem simples. Eles devem anunciar a todos, em todo lugar e circunstância, a boa nova ou benefício: pode-se ensinar aquilo que se ignora. Um pai de família pobre e ignorante pode, portanto, começar a instrução de seus filhos. Cabe, ainda, fornecer o princípio dessa instrução: é preciso aprender qualquer coisa e a isso relacionar todo o resto, segundo esse princípio: todas as inteligências são iguais" (RANCIÈRE: 2015: 141).

5 Marcos Bagno (1999) põe em questão aquilo que ele denomina de preconceito linguístico, decorrente justamente da separação drástica entre língua falada e gramática. 
Devido ao 'ódio à democracia' reinante em todos os segmentos da sociedade - notadamente nos grupos que empregam a palavra "democracia" com mais frequência, pompa e empáfia - ${ }^{6}$, a formação de inspiração democrática não costuma passar de um sonho de algumas noites de verão anuais; ou seja, somente durante as férias os estudantes se vêem relativamente livres da claustrofóbica, alienante e, por vezes, pedante formação de inclinação iluminista, ou mesmo a "pós-moderna". Não bastasse esse drama em nada shakespeariano, a formação em geral, qualquer que seja sua tendência pedagógica, é, atualmente, condicionada pelos ditames do capital. Sem poder entrar por ora na discussão acerca das "deformações", que vão do CA ao DO, às quais nós somos submetidos nas instituições de ensino - de Ivan Illich a Galdêncio Frigotto, passando por Paulo Freire e pelo próprio Jacques Rancière, não faltam belas e ricas propostas em direção à formação autenticamente libertária ${ }^{7}$-, o fato é que a educação como um todo tornou-se quase completamente refém, por assim dizer, da ilógica lógica capitalista de busca insana por resultados/lucros a qualquer preço, literal e literariamente falando: das escolas públicas de ensino fundamental premiadas por "alto desempenho" à 'Avaliação Capes' dos programas de pós-graduação sedentos por recursos financeiros, tudo faz parte de um sistema único de mercantilização da educação.

Ao abordar alhures especificamente o 'Capestalismo Lattesfundiarista' da pós-graduação, chamei esse processo de Síndrome da Ostensiva Mercantilização Acadêmica (SOMA), causa de adoecimento metafórico do sistema universitário e adoecimento real dos funcionários e docentes ${ }^{8}$; e, cada vez mais, até dos próprios discentes, por conta da exigência de que eles sigam, sob pena de punição explícita ou velada, o $1^{\circ}$ Mandamento das Profanas Escrituras: "Amar o Artigo Científico sobre todas as coisas".

\section{Dialética do enegrecimento}

Se a universidade fora outrora - em muitos aspectos, ainda o é - a 'torre de marfim' acessível a poucos privilegiados bem-nascidos, é quando o acesso a ela começa a relativamente se democratizar por meio de 'políticas afirmativas' que, paradoxalmente, transforma-se em uma 'jaula de aço' responsável por matar aos poucos o espírito e o coração daqueles aprisionados dentro dela; isso porque as leis que a regem hoje são, no final das contas, as mesmas que desgovernam o mercado de consumidores mundializado, sendo apenas travestidas de "inovações progressistas". ${ }^{9}$ Contudo, justamente em virtude das "invasões bárbaras" mais recentes, nós podemos acalentar a utopia, em seu sentido galeaniano, de implosão da 'jaula de aço' em que nos encontramos encarcerados. Por ironia solidária do "destino", mesmo a ainda tímida entrada dos considerados "invasores bárbaros" (mulheres, negras e negros, índias e índios, lésbicas, gays, entre outros "degenerados") já está sendo suficiente para renovar a atmosfera universitária de nuvens altamente carregadas, a ponto de podermos asseverar que, embora ainda seja um movimento de translação contra-hegemônico, nós estamos testemunhando o despertar de um novo sol de primavera: o Enegrecimento como superação do Esclarecimento Europeu. Com efeito, aqueles que sempre foram visto como "menores" pelas elites patrimonialistas e clientelistas, donas do poder até no interior da própria universidade, é que estão demonstrando potencial e 'empoderamento' para nos conduzir à verdadeira maioridade que, no fundo, o patriarcado branco jamais ousou instaurar entre nós; afinal, "Esclarecimento" foi, normalmente, um mero belo nome para a DOR (Dominação, Opressão e Repressão) imposta aos "bárbaros" e "primitivos". ${ }^{10}$

6 Em seu ensaio sobre o novo ódio à democracia reinante em nosso tempo, Rancière (2014:11) coloca a questão de modo incisivo: “[para a elite] só existe uma democracia boa, a que reprime a [assim considerada por ela, elite] catástrofe da civilização democrática".

7 Consciente da imbricação inextricável do capitalismo com as diferentes esferas da sociedade, é que Mészáros (2005) defendeu a tese de que uma educação genuinamente emancipatória não pode se concretizar no interior dos marcos do capital.

8 Cf. Mendonça, 2014.

9 Santos (2004) forneceu um excelente diagnóstico acerca das três principais crises atravessadas pela universidade (crise de hegemonia, de legitimidade e institucional) e, ao mesmo tempo, um prognóstico de superação destas, especialmente da crise institucional (como manter a autonomia e a responsabilidade social universitárias em tempos de critérios empresariais de avaliação?).

10 Até os próprios europeus de pendor mais autocrítico não deixaram de desnudar as verdadeiras motivações por trás do figurino engomado dos "esclarecidos": dentre outros desmascaramentos, Adorno e Horkheimer (1985) alertaram que várias das 
Nesse sentido, enegrecimento é o alvorecer de um novo tempo em que os "menores" passaram a ter, graças a uma longa história de luta, direito à sua própria voz na construção coletiva dos espaços democráticos. Normalmente, reconhecidas pela designação de "grupos identitários", ou analisadas sob o guarda-chuva das "políticas das diferenças", essas minorias não se calam mais diante das pessoas que queiram falar em seu lugar, como seus "representantes", sem que jamais tenham vivido sob sua condição histórica de discriminação e estigmatização, sem contar as variadas formas de violência (da escravidão à violência simbólica) de que foram e continuam sendo vítimas. ${ }^{11}$ E "claro" que dilemas e desafios, tanto teóricos quanto políticos, persistem. Para mencionar apenas dois: 1- Edward Said não se cansou de chamar a atenção para os riscos de se incorrer em novos tipos de essencialismo; 2- Ernesto Laclau nos lembrou do perigo de enfraquecimento político em função da fragmentação. Haveria algo comum - e.g.: luta de classes - por trás de todas essas lutas de gênero e étnicas específicas? Seja como for, os novos movimentos sociais, organizados sob a bandeira multicolorida de contraste entre identidade e diferença, estão sendo responsáveis por uma verdadeira reconfiguração do espaço público das arenas de disputa política. Não é à-toa que voltamos a viver, no mundo inteiro, sob a ameaça do conservadorismo e das forças reacionárias, como que em reação desesperada contra o advento justamente do enegrecimento.

Exemplificando: o Puta Dei (evento que tive a felicidade de participar no IMS, no dia 02 de junho de 2017, por ocasião do Dia Internacional das Prostitutas) mostrou, contundentemente, o quão formadora e transformadora é a fala daqueles que narram suas próprias experiências de luta e emancipação face a DOR. De fato, na mesa-redonda, composta por José Miguel Olívar (Unicamp/Pagu), Laura Lowenkron (IMS), Indianara Siqueira (Transrevolução, CasaNem, Davida, Câmara dos Vereadores) e Bete Guedes (Projeto "O que você não vê"/Davida/Observatório da Prostituição), destacaram-se bastante os próprios relatos de vida dessas duas últimas, ambos profundamente impactantes e marcantes pela autenticidade e 'coragem da verdade'. Sem contar a intervenção político-acadêmica, capaz de suscitar polêmicas mesmo em um ambiente supostamente "esclarecido" feito o espaço acadêmico, realizada pela performer Tertuliana Lustosa. ${ }^{12}$

Do exposto acima e ao aludir o Puta Dei, espero ter deixado "claro" que enegrecimento não diz respeito tão-somente à questão étnica e racial, mas, sim, às lutas por emancipação das "minorias" em geral, que, aliás, é uma palavra carregada de sentido e de uma história que remonta ao termo "menor" do qual Kant tratou em seu texto. Da mesma forma, torço para que minha incursão por essa temática não seja confundida com uma tentativa de teorizar em nome das pessoas que fazem parte desse "movimento" - atitude que seria incongruente com o reconhecimento de que os "menores" estão, e devem continuar cada vez mais, falando por si mesmos. Eu quero apenas, se tiver direito, reverberar suas vozes ainda silenciadas na academia e sociedade afora. E, se possível, encontrar uma forma consensuada de "falar com".

Note que, até onde eu estou cônscio, a expressão 'enegrecimento' com essa conotação de guarda-chuva abrigando toda a diversidade de movimentos das minorias reinvindicatórios de direitos está sendo empregada pela primeira vez aqui, o que pode vir a ser rechaçado como uma busca ilegítima de tentar dar uma unidade ilusória e forçosa a grupos contendo um conjunto de princípios e valores incomensuráveis entre si.

catástrofes da era moderna (entre elas, o nazismo) eram uma espécie de decorrência "natural" da razão instrumental supostamente esclarecida, e não um "desvio casual"; Feyerabend (2010) ironizou todos os males que o ocidente fez em nome da razão iluminista e do humanismo; e, finalmente, Kurz (2010) denunciou a atual retórica de inspiração iluminista em prol da "emancipação" contrastante com sua prática ainda colonialista e sanguinária.

11 Do ponto de vista da análise e interpretação acadêmicas, existem várias vertentes e autoras/autores - indo dos estudos subalternos ao feminismo interseccional, passando pelo decolonialismo - que abordam a temática referente à questão identitária. Para uma das referências mais influentes, conferir Spivak (2010).

12 Devo aqui congratular, pela bela e inspiradora iniciativa, as professoras Claudia Mora e Laura Murray e o professor Rogério Azize, responsáveis pela disciplina "Migração, Gênero e Saúde”, no interior da qual o referido evento foi realizado. 


\section{Relato de experiência sem experiência de relato ${ }^{13}$}

Sinto-me, salvaguardadas as devidas diferenças e proporções, tendo a oportunidade de estar experienciando até o momento sensação similar àquela narrada por Paul Feyerabend no final do seu transformador Adeus à Razão, em que ele revela a boa rasteira que tomou da vida ao ter travado contato em sala de aula com negras, negros, indías e índios que entraram na universidade por meio de políticas afirmativas, nos EUA da década de 1960: o que inicialmente fora visto como uma grande chance de "iluminar" ou "civilizar" os excluídos, logo passou a ser percebido por ele como uma ocasião ímpar de ele mesmo aprender e crescer com as ricas tradições das quais essas pessoas eram portadoras e guardiães. Mal comparando, ao chegar na saúde coletiva, e especificamente no IMS, eu também vibrei com a possibilidade de ensinar filosofia para pessoas de formações supostamente menos reflexivas (Kant já ensinara ser essa tarefa impossível, pois só se poderia ajudar a filosofar...); "será uma oportunidade singular de encontro entre as 'duas culturas': serei um 'humanista' interegindo com 'cientistas' da saúde", imaginava eu, tolamente. Ainda bem que logo de cara essa ilusão foi completamente desmascarada: meu primeiro co-orientando de mestrado, um ex-farmacêutico, mostrou-se muito mais propenso à reflexão e à crítica do que eu. ${ }^{14}$ "E agora, André? Que mera quimera você sonhou!" Acontece que foi justamente o encontro com a dura ou doce realidade a razão decisiva para minha relação profícua posterior com mestrandos e doutorandos: ao menos tal como vejo meu mundo, retrospectivamente, todos os processos de orientação têm sido de profundo e marcante aprendizado mútuo e horizontal.

Obviamente, minha mudança não se deu apenas como formador em termos de orientação. Como professor em sala de aula, "coincidentemente", foi também uma ex-farmacêutica a pessoa decisiva na minha reorientação de rumo: ter incentivado que eu desse um curso sobre os 'históricos' da saúde coletiva - eu referira a obra A Indústria da Saúde no Brasil, do Hésio Cordeiro, em um artigo que ela leu (olha a abservância do "1॰ Mandamento" aí...) - foi fator preponderante para que eu oferecesse a disciplina de nome meio burocrático "Fundamentos epistemológicos e políticos da saúde coletiva", que, logo em sua primeira edição, já virou, afetuosamente, "Como nossos pais e mães". ${ }^{15}$ Inclusive, no corrente ano de 2017, ela serviu de mote para uma oficina intitulada "Como nossos pais e mães: assumindo a autoria da saúde coletiva", realizada no $3^{\circ}$ Congresso de Política, Planejamento e Gestão em Saúde da Abrasco, no $1^{\circ}$ de maio, das 8 às 12h, em Natal (RN). Seus organizadores são os estudantes do IMS responsáveis por me fazerem descobrir na prática que a experiência formativa, incluindo a dos docentes, jamais tem fim quando se está aberto para o aprenzidado e transformação mútuos, regados a valores, sonhos e afetos. Faço questão de mencionar seus nomes, pois eles estarão para sempre gravados em meu coração: Alessandra Aniceto, Catalina Kiss, Gabriela Barreto, Gerson da Costa Filho, Leandro Gonçalves e Roberta Dorneles, a mesma da pergunta inquietante da roda de conversa referida no começo e também uma ex-farmacêutica (farmacêuticas e farmacêuticos de formação ainda deverão ser vistos como "menores" no campo da saúde coletiva após esses três exemplos e tantos outros que devem existir?). ${ }^{16}$

Valho-me aqui de excertos do resumo da própria proposta da oficina, uma vez que os estudantes, seus proponentes, sintetizaram melhor do que eu seria capaz o modus operandi da disciplina:

13 Conquanto, aqui, faça um breve relato apenas da minha experiência na pós-graduação - até porque leciono em um instituto onde ainda não há graduação -, eu não posso me furtar de lembrar o período em que dei aula de filosofia no ensino médio, antes de me tornar professor universitário. E aproveito para agradecer a Gustavo Bertoche, grande amigo que me indicou para trabalhar no colégio em que ele também dava aulas.

14 Seu nome é Leandro Gonçalves, que, aliás, tenho a sorte e o privilégio de tê-lo no momento como meu orientando de doutorado, prestes a defender uma tese sobre as grandes narrativas e micro-histórias do IMS contadas pelos seus próprios atores/ atrizes, i.e., professores, estudantes e funcionários.

15 Ela se chama Catalina Kiss, orientanda de doutorado do meu colega e amigo Paulo Henrique Rodrigues. Sua transformação íntegra e integral é, para mim, um caso singular e, simultaneamente, paradigmático de que a relação intensa e visceral com o conhecimento, quando cultivada pela potência do afeto e da sensibilidade, pode ser contagiante em termos coletivos.

16 Não posso deixar de reconhecer a importância de outros estudantes do IMS marcantes na minha trajetória até aqui: Daniela Lacerda, Gabriele Carvalho, Isabel Prado, Leandro dos Santos, Lucas Cabral, Manuelle Matias, Pedro Cavalcante e Thais de Andrade. 
Na primeira edição da disciplina, no primeiro semestre de 2015, docente e discentes puderam eleger os clássicos das décadas de 70 e 80 que leríamos. Rapidamente, vimos que o potencial de obras como "Medicina e Sociedade", de Donnangelo, "O Dilema preventivista”, de Arouca, "As Instituições Médicas no Brasil”, de Madel Luz, não se desmanchou no ar. A leitura coletiva destas e outras obras nos tomou dois anos, anos nos quais a disciplina permaneceu viva, por quatro edições, congregando cerca de 30 discentes, de diferentes instituições acadêmicas e não acadêmicas (...). A disciplina está entre as eletivas da grade curricular do departamento de Política, Planejamento e Administração em Saúde. Logo, bastante situada entre as atividades do IMS. A participação na disciplina era aberta à Comunidade do IMS e da Saúde Coletiva, independente da inscrição regular em cursos de pós-graduação. O mote era trabalharmos com textos clássicos ou que nos fizessem lidar com a conjuntura atual de modo crítico - pressuposto que perpassa os textos clássicos da área, da década de 70 e 80 . Deste modo, não se propunha uma bibliografia à priori, isto era decidido entre os participantes da disciplina, na primeira aula do curso. As primeiras aulas eram aquelas em que nos apresentávamos e nos reconhecíamos coletivamente. Os textos eram apresentados, nas aulas, de diferentes maneiras, pelos discentes. Aquela que predominou, foi baseada na ideia de Defesa de Tese, em que um de nós defendia a obra e outros três faziam a crítica.

Pela participação ativa dos estudantes até mesmo na decisão das obras a serem discutidas, espero ficar patente que o nosso principal pressuposto pedagógico consiste na ideia de que formar não é querer encaixar alguém supostamente inferior em uma fôrma rígida e fechada; formar é, antes de tudo, permitir-se estar em processo permanente de co-formação rumo à superação da conformação, pois o que importa mesmo é mudar o mundo ao redor e transformar a si próprio, especialmente quando temos sentimento de pertença a uma coletividade que amamos, por pequena que seja. Creio que o que é válido para a pós-graduação, onde as pessoas já possuem uma formação profissional prévia, também deve contar como apropriado, reconhecendo as devidas especificidades de cada ciclo educativo, para a formação desde o ensino fundamental. Paulo Freire e seus colegas de concepção dialética da educação já o demonstraram lindamente: formação nunca é, ou deveria ser, transmissão vertical de conteúdos prontos e acabados; ela deveria ser um processo infindável de criação coletiva em direção à autonomia do indivíduo e à emancipação humana por meio da interregoção permanente do status quo, visando sempre à contrução de um mundo onde prevaleçam a igualidade substantiva, a liberdade coletiva e a solidariedade desinteressada.

\section{Patrimônio Público, Popular e Plural (Pppp!) x "Parceria" Público-Privada (PpP?)}

Sou suspeito, porém, para mim, experiências de co-formação com pontencial transformador como a relatada sucintamente acima só são possíveis, a rigor, em universidades públicas. Sou mais suspeito ainda, mas, sem sombra de dúvida, a UERJ é a universidade por excelência na qual pode se dar a fusão de horizontes amplificadora das vozes de quem não tem vez e ampliadora da nossa visão de mundo. Pioneira na política de cotas e nos projetos sociais para os excluídos da sociedade carioca, sem contar as pesquisas que alavancam o desenvolvimento sócio-econômico do nosso estado, a UERJ é o exemplo paradigmático de que os "invasores bárbaros" são os verdadeiros responsáveis pela nossa maior 'civilidade', para usar a expressão predileta dos opressores, subvertendo-a. De fato, estou na UERJ desde o período pré-cota e sei o quanto a entrada dos cotistas fez mais bem ainda à universidade que, também na vanguarda, já oferecia cursos noturnos faz tempo, o que, inclusive, deu-me condições de fazer filosofia, já que eu trabalhava durante o período da minha graduação. É esse patrimônio da população fluminense que está sob risco e ameaça nesse momento dramático em que o Pezão usa sua mãozão de tesoura para cortar diversos serviços básicos, aos quais cidadãs e cidadãos têm direito; além de tentar inviabilizar nossa universidade e as demais universidades estaduais para "legitimar" uma provável privatização, ou, "na melhor das hipóteses", o avanço da enganosa "Parceria" Público-Privado (PPP). A julgar pela brava e incansável resistência de toda a comunidade uerjiana, nossa universidade vai sair mais fortalecida ainda dessa crise, a mais grave de sua história até aqui. Sendo a UERJ uma espécie de 
balão de ensaio para privatizações de outras estaduais, e mesmo federais, sua resistência representa, no fundo, uma ofensiva contra o governo golpista e ilegítimo do Temer e inominável do Pezão. Parafraseando Mario Quintana, Temer e Pezão passarão, nós passarinhos! ${ }^{17}$

Eu tenho um sonho: em breve, nossa universidade vai estar recebendo de braços abertos os estudantes secundaristas que fizeram parte das ocupaçãos das escolas cariocas e do Brasil afora em 2015/2016. Para mim, eles são as 'flores belas' que brotaram pós Primavera do Junho de 2013. Que lição de vida e de luta eles nos deram! Meu sonho é ter o bom privilégio de poder, dentro de alguns anos, vir a orientar (ou serão eles meus verdadeiros orientadores?) essas pessoas tão jovens e, ao mesmo tempo, tão maduras em cidadania. Tenho a convicção de que eles terão paciência para me transformarem em uma pessoa melhor e em um "desorientador" e professor mais bem cultivado do que agora no enegrecimento, pois saberão que fui simbolicamente violentado no esclarecimento europeu, como se eu não fosse fruto de uma família de nove irmãos retirantes do Recôncavo Baiano, nos idos de 1950. Com eles, sei que poderei cultivar saberes, valores, ideias e ideais pelos quais valha a pena lutar. Não obstante essa promissora troca, meu sonho mesmo é que esses "enegrinistas", por terem desde cedo experienciado a luta política e o conflito aberto, é que saberão refundar nossas instituições e recriar novos vínculos coletivos. Seja como for, no fundo, o sonho agora é e será sonhado por eles mesmos. Que nos tragam a volta da utopia, sem a qual não me parece fazer sentido a luta política...

Assim como o esclarecimento foi fundamental para a construção do chamado projeto da modernidade, possa o enegrecimento reconstruir, ao fim e ao cabo, a própria "civilização", ensejando um novo começo de era em que, finalmente, haja mais liberdade coletiva, mais justiça social e, por que não dizer, mais fraternidade. Como já externei, minha esperança e utopia são enraizadas nas Primaveras ao redor do mundo - da Primavera Árabe à Primavera Estudantil Brasileira, passando pela terceira onda feminista -, após o grande inverno russo do imperialismo norte-americano e europeu.

Por fim, creio que a pergunta "o que é formação?", norteadora de qualquer projeto civilizatório que se preze, deva começar a ser respondida principalmente pelos próprios estudantes, do ensino fundamental ao doutorado. Eu só me permitiria sugerir que ela fosse ligeiramente modificada por "para que formação?". Afinal, o "para que" poderá contribuir com que as questões de sentido varridas para debaixo do tapete desde tempos idos possam voltar às claras, ou melhor, "às escuras" do Enegrecimento.

\section{Agradecimentos}

A Ricardo Barbosa, por ter sido o primeiro professor a chamar a minha atenção para os textos de Kant e de Foucault sobre o esclarecimento, durante a minha graduação. A Gustavo Saboia, pela gentileza de ter me enviado o original e novas traduções do texto de Kant discutido aqui, e, por extensão, a André Rios, seu orientador, pelas nossas edificantes conversações filosóficas. À Gabriela Barreto, por uma conversa em que, pela primeira vez, ocorreu-me a ideia de enegrecimento, graças à sua crítica (sempre certeira) ao racismo velado de termos tais como "esclarecimento". À Gulnar Azevedo, diretora do IMS, por propiciar todas as condições, mesmo nesse momento tão difícil atravessado pela UERJ, para que eu e demais jovens professoras e professores possamos defender nossas ideias e cultivar nossos ideiais no instituto. Por último, mas mais importante, à Katia Reis, por ter infundido em minha alma o espírito libertário de Paulo Freire.

17 Em carta ao Comando de Greve/Comando de Mobilização da UERJ, redigida no ano passado por ocasião do término de uma greve longa e difícil, fiz um 'agradecimento pelo engrandecimento' dirigido aos meus colegas uerjianos, motivo de grande orgulho e esperança. Por falta de espaço, destaco aqui alguns nomes: Ana Karina Brenner, Cleier Marconsin, Deborah Fontenelle, Eduardo Torres, Francisco Sousa, Frederico Irias, Guilherme Leite, Guilherme Mota, Guilherme Vargues, Isabel Cardoso, Jefferson Ruiz, Lia Rocha, Luiz Santa Maria, Luiz Ricardo Leitão, Paulo Alentejano, Renê Forster, Rodrigo dos Reis e Rosineide de Freitas. 


\section{Referências Bibliográficas:}

ADORNO, Thedor; HORKHEIMER, Max. Dialética do esclarecimento: fragmentos filosóficos. Tradução: Guido Antonio de Almeida. Rio de Janeiro: Jorge Zahar Ed., 1985.

BAGNO, Marcos. Preconceito linguístico: o que é,como se faz. São Paulo: Edições Loyola, 1999.

CAMBI, Franco. História da pedagogia. Tradução: Álvaro Lorencini. São Paulo: Unesp, 1999.

FEYERABEND, Paul. Adeus à razão. Tradução: Vera Joscelyne. São Paulo: Unesp, 2010.

FOUCAULT, Michael. O que são as luzes?,inArqueologia das ciências e histórias dos sistemas de pensamento. Tradução: Elisa Monteiro. $3^{\text {a }}$ Ed. Rio de Janeiro: Forense Universitária, 2015. (Ditos \& escritos: 2).

KANT, Immanuel.; et al. O que é esclarecimento? Tradução: Paulo César Gil Ferreira. 1a ed. Rio de Janeiro: Via Verita, 2011.

KURZ, Robert. Razão sangrenta: ensaios sobre a crítica emancipatória da modernidade capitalista e seus valores ocidentais. Tradução: Fernando R. de Moraes Barros. São Paulo: Hedra, 2010.

MORROW, Raymond; TORRES, Carlos Alberto. Teoria social e educação: uma crítica das teorias da reprodução social e cultural. Tradução: Tiago Neves. Porto: Edições Afrontamento, 1997.

MENDONÇA, André. Dos Valores de Medida aos Valores como Medida: Uma avaliação axiológica da avaliação acadêmica, in Ensaios Filosóficos, Vol. X, 2014.

MÉSZÁROS, István. A educação para além do capital. Tradução: Isa Tavares. São Paulo: Boitempo, 2005.

RANCIĖRE, Jacques. O ódio à democracia. Tradução: Mariana Echalar. 1a ed. São Paulo: Boitempo, 2014.

. O mestre ignorante - cinco lições sobre a emancipação intelectual. Tradução: Lílian do Valle. $3^{a}$ ed. Belo Horizonte: Autêntica Editora, 2015.

RIOS, André. Kant em coma. Rio de Janeiro: 7Letras, 2006.

SANTOS, Boaventura. A universidade no século XXI: para uma reforma democrática e emancipatória da universidade. São Paulo: Cortez, 2004.

SPIVAK, Gayatri. Pode o subalterno falar? Tradução: Sandra Regina Goulart, Marcos Pereira Feitosa e André Pereira Feitosa. Belo Horizonte: Ed. UFMG, 2010.

WEBER, Max. Ciência e política: duas vocações. Tradução: Leonidas Hegenberg e Octany Silveira da Mota. 17a ed. São Paulo: Editora Cultrix, 2011. 